\title{
The Impact of Financial Liquidity on the Exchange Rate of the Chinese Yuan Renminbi against the United States Dollar under Interest Rate Liberalization - Evidence from Shibor
}

\author{
Zhenyu $\mathrm{Wu}^{1} \&$ Maoguo $\mathrm{Wu}^{1}$ \\ ${ }^{1}$ SHU-UTS SILC Business School, Shanghai University, China \\ Correspondence: Maoguo Wu, SHU-UTS SILC Business School, Shanghai University, 20 Chengzhong Road, \\ Jiading District, Shanghai 201899, China.
}

Received: March 8, 2018

Accepted: March 26, 2018

Online Published: March 30, 2018

doi:10.5539/ijef.v10n5p87

URL: https://doi.org/10.5539/ijef.v10n5p87

\begin{abstract}
Financial liquidity is one of the most important factors that affects China's currency market along with other macroeconomic factors. Shanghai Interbank Offered Rate (Shibor) is the quantitative indicator of the financial liquidity of China's capital market. China has been continuously promoting the marketization of interest rates. The interbank market, as a resource of money supply, is significantly affected by this process. This paper empirically investigates the relationship between Shibor and the onshore renminbi-dollar exchange rate utilizing data from October 2006 to January 2015. Furthermore, in addition to Shibor, inflation rate difference, benchmark interest rate difference, GDP growth rate difference, and trade balance are all included as control variables. First, preliminary tests such as the ADF test and Granger causality test were conducted for selecting the most appropriate regression method. A VAR test, impulse response, and variance decomposition were then conducted. Empirical results show that Shibor has a significant impact on the onshore renminbi-dollar exchange rate, exhibiting a one-way causal relationship with an inverse direction. Furthermore, other control variables also show a different relationship to the onshore renminbi-dollar exchange rate to some extent. The finding is consistent with classical theory and practical judgment. This paper contributes to existing literature on classical theory testing of the exchange rate and provides new evidence on the influencing factors of the exchange rate.
\end{abstract}

Keywords: financial liquidity, Shibor, exchange rate, time series

\section{Introduction}

In recent years, China has consistently been promoting the marketization of interest rates. The interbank market, as a money supply, is significantly affected by this process. As the most important measurement of the liquidity of China's interbank market, Shanghai Interbank Offered Rate (Shibor) is a crucial reference for decisions on capital supply. Currently, Shibor is generally accepted by Chinese commercial banks, whose liquidity is directly reflected by the fluctuation of Shibor.

Utilizing data from October 2006 to January 2015, this paper empirically investigates the relationship between the onshore renminbi-dollar exchange rate and Shibor. Empirical results find that Shibor has a significant negative impact on the onshore renminbi-dollar exchange rate. Furthermore, other influencing factors also to some extent exhibit an impact on the onshore renminbi-dollar exchange rate. Policy implications on improving the Shibor mechanism and promoting the marketization of the exchange rate are proposed accordingly.

The remaining part of this paper is organized as follows. Section 2 reviews related literature. Section 3 is devoted to empirical analysis. Section 4 interprets empirical results and proposes policy implications. Section 5 concludes the paper.

\section{Related Literature}

Shibor is a quantitative indicator of the liquidity of China's interbank market, and the interbank offered rate is an important reference factor on the money supply situation. A great deal of literature pertains to the relationship between the exchange rate and the benchmark interest rate. Only a partial selection of literature is briefly mentioned here. By using the GARCH model, McKinnon and Ono (1999) find that the inflation rate is higher under the floating exchange rate system and people's expectation of inflation rises correspondingly. The 
subsequent level of inflation compensation required in this situation increases accordingly. Meanwhile, the long-term nominal interest rate rises as well, to a level significantly higher than the short-term nominal interest rate. Baxter (1993) investigates the relationship between real interest rates and real exchange rates. Empirical results show that there is a long-term positive cointegration between the real interest rate and the real exchange rate, and the long-term cointegration is, furthermore, more significant in the period when the macro economy and the external environment fluctuate frequently.

For their part, Krugman and Obstfeld (1997) summarize factors and conditions of the real interest rate parity based on the theory of relative purchasing power parity and the theory of interest rate parity. They find that the expected depreciation rate of home currency is close to the actual home and foreign interest rate difference, therein exhibiting consistency to a certain degree. Engel (2011) further explores the theory of interest rate parity by empirically studying the correlation between the real interest rate, the real exchange rate, and the risk premium. Empirical results find that when a country's interest rate is at a high level, the country's monetary value demonstrates a stronger performance. This strength is nevertheless only temporary. Over time, the country's currency will devalue and eventually arrive at its long-term price level.

Then there's Raymond (2001), who studied the correlation and the linkage effect between exchange rates and interest rates in the United States. He concludes that there is a significant correlation and significant interaction between exchange rates and benchmark interest rates in the United States. In addition, exchange rates have a greater impact on benchmark interest rates. Utilizing data from Thailand, Shen (2002) extends on the MundellFleming model and finds that the main determinants of the exchange rate fluctuation are macroeconomic variables such as the interest rate, the money supply, and GDP when the money market and the commodity market are in equilibrium. In addition, exchange rates and interest rates have significant correlation and they change in the same direction. However, if relevant economic variables and the external environment change, the direction of the relationship between the exchange rates and interest rates may well change. By analyzing exchange rates and benchmark interest rates from the United States from 1870 to 2006, Dreger (2009) finds that the situation in the United States is very close to the theory of real interest rate parity. The temporary impact of the interest rates on exchange rates is significant, but the correlation between exchange rates and interest rates tends to be stable in the long run. As a result, the impact of interest rates on exchange rates is less significant in the long run.

Further work of consideration comes from Xue (2003), who analyzes the linkage between the renminbi-dollar exchange and China's interest rate in an open financial market environment. He concludes that the degree of openness of the financial market, change of interest rate system, and the exchange rate system ultimately affect the linkage mechanism of the exchange rates and interest rates. At the same time, asset conversion likewise has an impact on the linkage mechanism. Wong and Lin (2007) derive regularities in the periodic change of the nominal exchange rate and nominal interest rate, and conclude that a correlation exists between these two variables. They conclude that with the continuous development of marketization, the relationship between the renminbi-dollar exchange rates and China's interest rates will become stronger. Yang (2011) conducts a Granger causality test and finds that there is a two-way causality present between the renminbi-dollar exchange rates and interest rates. Impulse response and variance decomposition find that the linkage effect between the renminbi-dollar nominal effective exchange rate and Shibor is more significant in the long run than in the short run. In addition, Shibor's impact on the renminbi-dollar nominal effective exchange rate is significantly greater, not vice versa.

Most previous studies investigate the exchange rates of currencies of developed countries or mature economies, which are characterized by free capital flow and a floating exchange rate. To that end, different conclusions were drawn even in case the same quantitative method was utilized to investigate the exchange rates of the different currencies. Hence, previous research results about other exchange rates of currencies cannot be applied directly to the exchange rate of renminbi. Furthermore, most previous research on the renminbi-dollar exchange rate is confined to China's nominal renminbi-dollar exchange rate and nominal benchmark interest rate, while the relationship between the onshore renminbi-dollar exchange rate and the interbank offered rate is rarely studied.

\section{Empirical Analysis}

Shibor is used as the quantitative index of the financial liquidity of China's banks. It constitutes the average of the interbank lending rates given by several banks with reliable credit, officially approved by People's Bank of China. Shibor can be classified as overnight, 1 week, 2 weeks, 1 month, 3 months, 6 months, 9 months, and 1 year in duration. There are currently 18 commercial banks offering Shibor. These banks fully meet the qualification of suppliers in the primary market, and trade frequently in the money market with considerable 
transaction volume. In addition, their required information disclosure is more standardized, which is supervised by the People's Bank of China. In calculating the daily Shibor quote, the highest four quotes and the lowest four quotes are excluded and the remaining quotes are averaged mathematically. The quote for each time period is calculated in accordance with this rule. The quoted price of the current period is published at 9:30 a.m. in the following day after banks settle the daily balance of payments. This paper utilizes the data from overnight Shibor, the most commonly traded Shibor. Since the Shibor quotation mechanism was put into practice in late 2006, this paper gathers the monthly data of the mathematical average quote of Shibor from October 2006 to December 2015, resulting in 111 months of data.

The onshore renminbi-dollar exchange rate is the explained variable. This paper adopts the middle price of the renminbi-dollar exchange rate issued by the China Foreign Exchange Trade System (CFETS). The price is the exchange rate of the U.S. dollar against the renminbi under the direct quotation. In line with the time period of Shibor, this paper selects the monthly data of the average renminbi-dollar exchange rate from October 2006 to December 2015.

The theory of interest rate parity states that the interest rate differential between the two countries is equal to the differential between the forward exchange rate and the spot exchange rate. This paper therefore takes the difference between the two benchmark interest rates (U.S. benchmark interest rates minus China benchmark interest rates) as a control variable. It utilizes the one-year benchmark lending rate from October 2006 to December 2015 as China's benchmark interest rates, and the Federal Funds Rates from October 2006 to December 2015 as the U.S. benchmark interest rates. The data are gathered from the National Bureau of Statistics of China and the Federal Reserve.

Following the theory of purchasing power parity, the difference in the inflation rates between the United States and China is an influencing factor in the renminbi-dollar exchange rate. Monthly CPI data from the United States and China from October 2006 to December 2015 are gathered from the U.S. Bureau of Labor Statistics and National Bureau of Statistics of China, respectively. The formula is as follows:

$$
\mathrm{T}=\left(P_{t}-P_{t-1}\right) / P_{t-1}
$$

where $P_{t}$ is the CPI of a certain month, and $P_{t-1}$ is the CPI from the previous month. The monthly inflation difference between the United States and China (US inflation rate minus China inflation rate) stands as a control variable.

Then, following the DDAA model, the difference in GDP growth rates between the United States and China becomes an influencing factor in the renminbi-dollar exchange rate. Quarterly GDP data from the United States are gathered from the World Bank, while quarterly GDP data from China are gathered from the National Bureau of Statistics of China. The time period is between October 2006 and December 2015. Since the frequency of time in this paper is monthly, quarterly data are converted into monthly data by the method of Frequency Conversion-Cubic Match Last. The monthly GDP growth rate is then calculated. The monthly GDP growth difference between the United States and China (monthly GDP growth of United States minus monthly GDP growth of China) is subsequently obtained.

The trade balance between the United States and China is another influencing factor. This paper collects the monthly trade balance data between the United States and China from October 2006 to December 2015 from the Chinese Ministry of Commerce and U.S. Department of Commerce. It is selected as another control variable. During this time period, China maintained a trade surplus.

In order to avoid spurious regression, a stationarity test is conducted first. This paper employs the Augmented Dickey-Fuller (ADF) test. The result is shown in Table 1.

Table 1 . ADF test of stationarity

\begin{tabular}{lcccccc}
\hline \multirow{2}{*}{ Variables } & \multirow{2}{*}{ ADF Statistic } & \multicolumn{3}{c}{ Critical Value } & \multirow{2}{*}{ P-Value } & Conclusion \\
\cline { 3 - 6 } & & $1 \%$ & $5 \%$ & $10 \%$ & & \\
\hline Shibor & -4.240965 & -3.490772 & -2.887909 & -2.580908 & 0.0009 & Stationary \\
Renminbi-Dollar Onshore Exchange Rate & -3.318479 & -3.491345 & -2.888157 & -2.581041 & 0.0164 & Stationary \\
$\begin{array}{l}\text { Difference of Benchmark Interest Rate between } \\
\text { United States and China }\end{array}$ & -3.152973 & -3.491928 & -2.888411 & -2.581176 & 0.0257 & \multirow{2}{*}{ Stationary } \\
$\begin{array}{l}\text { Difference of Growth Rate of GDP between } \\
\text { United States and China }\end{array}$ & -1.854282 & -3.496346 & -2.890327 & -2.582196 & 0.3526 & \multirow{2}{*}{ Not Stationary } \\
\hline
\end{tabular}




\begin{tabular}{lllllll}
\hline First Difference of Difference of Growth Rate of & -5.738114 & -3.499167 & -2.89155 & -2.582846 & 0 & Stationary \\
GDP between United States and China & -0.218251 & -3.498439 & -2.891234 & -2.582678 & 0.9314 & Not Stationary \\
$\begin{array}{l}\text { Trade Balance between United States and China } \\
\text { First Difference of Trade Balance between }\end{array}$ & -3.475699 & -3.498439 & -2.891234 & -2.582678 & 0.0107 & Stationary \\
United States and China & & &
\end{tabular}

It can be seen in Table 1 that the p-values of the renminbi-dollar onshore exchange rate, Shibor, the difference in inflation rates, and the difference in benchmark interest rates that are less than 0.05 , indicating that these variables are stationary. Two variables, a difference in the growth rate of GDP and the trade balance become stationary after taking first-order difference.

The Granger causality test is performed on all selected variables. The p-value of the hypothesis is that the renminbi-dollar onshore exchange rate is not a Granger cause of Shibor is 0.0988 , so the hypothesis is not rejected. The p-value of the hypothesis that Shibor is not a Granger cause of the renminbi-dollar onshore exchange rate is 0.0298 , so the hypothesis is rejected accordingly. Hence, a one-way causal relationship can be detected between the liquidity of the Chinese interbank market and the renminbi-dollar onshore exchange rate, i.e., Shibor has a significant impact on the fluctuation of the renminbi-dollar onshore exchange rate, while the transmission mechanism of the exchange rate to the liquidity of the interbank market is not significant. On the one hand, this one-way causal relationship is due to the regulation of capital accounts, which serves to restrict capital flow and hinders the transmission process of the exchange rate. On the other hand, the marketization of the interest rate is still insufficient due to role played by specific institutions in China.

Similarly, the difference in benchmark interest rates between the United States and China is a Granger cause of the renminbi-dollar onshore exchange rate, and the exchange rate is also a Granger cause of the difference in benchmark interest rates. Hence, the difference in benchmark interest rates and the exchange rate feature a two-way transmission mechanism. This finding also confirms the close relationship which exists between monetary policy and the exchange rate of the two countries.

In addition, test results show that the difference in inflation rates between the United States and China is a Granger cause of the renminbi-dollar onshore exchange rate, while the renminbi-dollar onshore exchange rate is a Granger cause of the difference in inflation rates between the United States and China. Similar to the difference in benchmark interest rates, the exchange rate and the inflation rate have interacting effects as well, indicating a two-way causal relationship.

Nevertheless, the difference of GDP growth rates between the United States and China, along with the trade balance between the United States and China features no significant causal relationship with the renminbi-dollar onshore exchange rate. We can therefore conclude that there is no direct two-way causal relationship between them, since both GDP and the trade balance are macro data, and the transmission effect on exchange rate is generally indirect, affecting the exchange rate by influencing other economic factors.

Granger causality test results show that the two variables, the difference in GDP growth rates between the United States and China, and the trade balance between the United States and China, have no causal relationship to the renminbi-dollar onshore exchange rate, while another two variables, namely, the difference in inflation rates between the United States and China and the difference in benchmark interest rates between the United States and China, have a causal relationship to the renminbi-dollar onshore exchange rate. It follows then, that, in order to avoid loss of information on the time series caused by differencing, this paper directly employs the original time series and establishes a VAR test for analyzing the relationship among the variables. The VAR test results are shown in Table 2.

Table 2. VAR test

\begin{tabular}{lccc}
\hline & $\begin{array}{c}\text { Renminbi-Dollar Onshore } \\
\text { Exchange Rate }\end{array}$ & $\begin{array}{c}\text { Difference of Inflation } \\
\text { Rates between United } \\
\text { States and China }\end{array}$ & $\begin{array}{c}\text { Difference of Benchmark } \\
\text { Interest Rates between } \\
\text { United States and China }\end{array}$ \\
\hline Renminbi-Dollar Onshore Exchange Rate & 1.174728 & 4.604577 & 0.929727 \\
$(-1)$ & -0.10269 & -2.45474 & -0.72944 \\
& {$[11.4398]$} & {$[1.87579]$} & {$[1.27458]$} \\
Renminbi-Dollar Onshore Exchange Rate & -0.223079 & -4.305126 & -1.074668 \\
$(-2)$ & -0.09775 & -2.3366 & -0.69433 \\
& {$[-2.28222]$} & {$[-1.84248]$} & {$[-1.54777]$} \\
\hline
\end{tabular}




\begin{tabular}{lccc}
\hline Difference of Inflation Rates between & -0.007964 & 0.921476 & 0.096014 \\
United States and China (-1) & 0.00401 & -0.09591 & -0.0285 \\
& {$[-1.98592]$} & {$[9.60789]$} & {$[3.36897]$} \\
Difference of Inflation Rates between & -0.001772 & -0.162201 & -0.027175 \\
United States and China (-2) & -0.0041 & -0.09808 & -0.02915 \\
& {$[-0.43181]$} & {$[-1.65374]$} & {$[-0.93240]$} \\
Difference of benchmark interest rates & 0.027406 & 0.377838 & 0.706497 \\
between United States and China (-1) & -0.01389 & -0.33192 & -0.09863 \\
& {$[1.97309]$} & {$[1.13834]$} & {$[7.16301]$} \\
Difference of benchmark interest rates & 0.006347 & -0.524518 & 0.290936 \\
between United States and China (-2) & -0.01388 & -0.33191 & -0.09863 \\
& {$[0.45713]$} & {$[-1.58032]$} & {$[2.94986]$} \\
C & 0.373541 & -2.796545 & 0.996118 \\
& -0.096 & -2.29477 & -0.6819 \\
Shibor & {$[3.89120]$} & {$[-1.21866]$} & {$[1.46079]$} \\
& -0.007597 & -0.05736 & 0.004969 \\
First Difference of Difference of GDP & -0.00327 & -0.07809 & -0.0232 \\
Growth Rates between United States and & {$[-2.32550]$} & {$[-0.73455]$} & {$[0.21414]$} \\
China & 0.07052 & -0.117497 & -0.183728 \\
First Difference of Trade Balance between & -0.08773 & -2.09722 & -0.6232 \\
United States and China & {$[0.80381]$} & {$[-0.05603]$} & {$[-0.29481]$} \\
& $-6.32 \mathrm{E}-07$ & $-9.72 \mathrm{E}-07$ \\
& $-9.20 \mathrm{E}-07$ & $-6.50 \mathrm{E}-06$ \\
& {$[-0.68971]$} & $-2.20 \mathrm{E}-05$ & {$[-0.14930]$} \\
& 0.997074 & {$[0.80575]$} & 0.982451 \\
\hline
\end{tabular}

Regression results show that the difference in inflation rates between the United States and China has a negative relationship with the renminbi-dollar onshore exchange rate. An increase in this difference means that the rate of inflation in the United States is higher than that in China. Following the theory of purchasing power parity and the theory of balance of payment, a rise in the inflation rate of the other country means an increase in the domestic money supply, which subsequently leads to a devaluation of the domestic currency and falling exchange rates. Based on this analysis, the renminbi-dollar onshore exchange rate rises. Meanwhile, a high inflation rate is often underpinned by a country's loose monetary policy. Thus, in terms of interest rate parity, low benchmark interest rates cause domestic capital to flow to other countries which offer higher benchmark interest rates in the hope of obtaining higher return on fixed income investment in other countries. This increases the supply of a country's currency and the demand for other currencies, further accelerating the decline of the exchange rate of the country's currency. As a result, this eventually pushes up the renminbi-dollar onshore exchange rate.

In addition, the difference in benchmark interest rates between the United States and China is positively correlated with the renminbi-dollar onshore exchange rate. An increase in benchmark interest rates means that the benchmark interest rate in the United States is higher than that in China. According to the theory of interest rate parity and the theory of balance of payments with full and free international capital flow, investors seek to invest in countries with high interest rates in order to obtain higher return on fixed income investment, and hold onto currency with a high interest rate in order to avoid an exchange rate risk from other currencies. On that account, the relative rise in the U.S. benchmark interest rates may lead to an increase in the demand for the U.S. dollar, which then pushes up the dollar-renminbi onshore exchange rate (pushing down renminbi-dollar exchange rate).

This paper further conducts an impulse response test and a variance decomposition test in order to examine impact direction, degree, and time lag of variables in the VAR test. The impact levels of the two variables, the difference in inflation rates between the United States and China, and the difference in the benchmark interest rates between the United States and China, along with the onshore renminbi-dollar exchange rate, are all examined accordingly. The stability of the variables is tested first. AR roots graph is shown in Figure 1. 


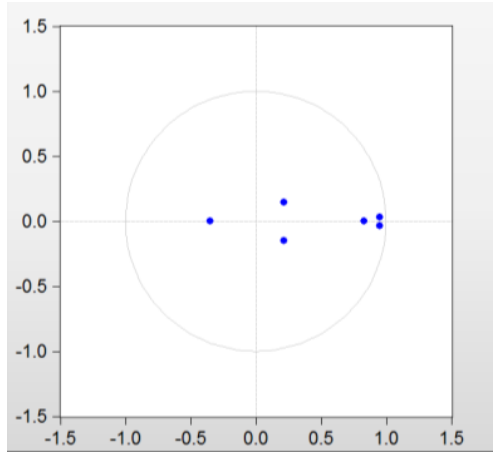

Figure 1. Inverse roots of AR characteristic polynomial

Test results show that characteristic roots of the VAR test are distributed within the unit circle. It follows then, that the VAR test is stable. An impulse response test and a variance decomposition test are carried out next.

Impulse responses of the onshore renminbi-dollar exchange rate to the difference in inflation rates between the United States and China and the difference in benchmark interest rates between the United States and China are shown in Figure 2 and Figure 3.

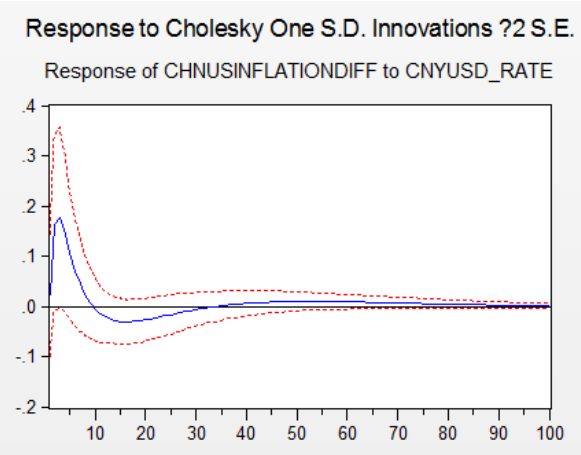

Figure 2. Impulse responses to difference in inflation rates

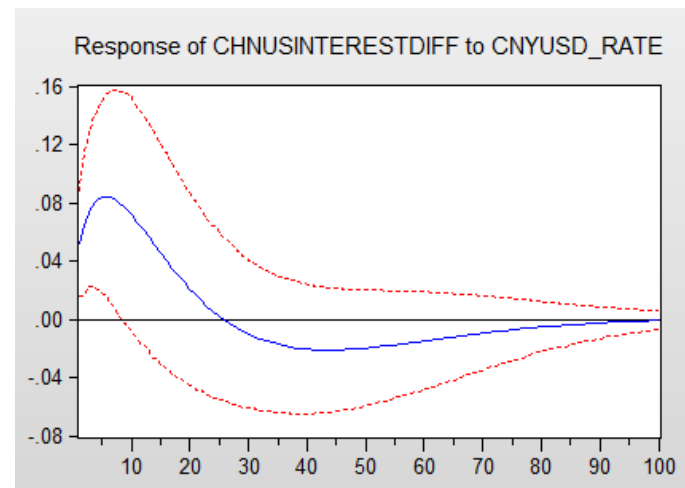

Figure 3. Impulse responses to a difference in benchmark interest rates

Figure 2 is a graphical depiction of the impulse responses of the onshore renminbi-dollar exchange rate to a difference in inflation rates between the United States and China. It shows that impulse responses rise at first, and then decline after reaching a peak of about 0.18 . Impulse responses become negative after the $10^{\text {th }}$ period, and further decrease to a minimum of about -0.03 in the $15^{\text {th }}$ period. Impulse responses gradually rise and become positive again in the $35^{\text {th }}$ period.

Figure 3 depicts the impulse responses of the onshore renminbi-dollar exchange rate to a difference in the benchmark interest rates between the United States and China. Impulse responses rise at first, and then start to 
decline after reaching a peak at of about 0.08 . Impulse responses become negative after the $25^{\text {th }}$ period, and further decrease to the minimum level at about -0.02 in the $43^{\text {rd }}$ period. Impulse responses gradually rise to 0 and then remain stable.

Comparing Figure 2 with Figure 3, it can be found that the effect of the difference in the inflation rates between the United States and China on the onshore renminbi-dollar exchange rate is greater than that of the difference in benchmark interest rates between the United States and China, which shows that inflation rate, determined by macro economy and market condition, feature a higher degree of explanation of the fluctuation of the onshore renminbi-dollar exchange rate than the benchmark interest rate, artificially set by the Central Bank.

Variance decomposition test results of difference in inflation rates between the United States and China and the difference in benchmark interest rates between the United States and China are shown in Table 4 and Table 5, respectively.

Table 4. Variance decomposition of difference in inflation rates between the United States and China

\begin{tabular}{ccccc}
\hline Period & S.E. & $\begin{array}{c}\text { Onshore Renminbi-Dollar } \\
\text { Exchange Rate }\end{array}$ & $\begin{array}{c}\text { Difference in Inflation Rates } \\
\text { between United States and China }\end{array}$ & $\begin{array}{c}\text { Difference in Benchmark Interest Rates } \\
\text { between United States and China }\end{array}$ \\
\hline 1 & 0.026771 & 0.124962 & 99.87504 & 0.68322 \\
2 & 0.042022 & 3.461325 & 95.93392 & 0.60475 \\
3 & 0.053784 & 5.635784 & 93.82768 & 0.536531 \\
4 & 0.0639 & 6.709413 & 92.80761 & 0.482974 \\
5 & 0.073055 & 7.148602 & 92.39269 & 0.458712 \\
6 & 0.081519 & 7.299044 & 92.2157 & 0.485261 \\
7 & 0.089395 & 7.324618 & 92.10436 & 0.57102 \\
8 & 0.096731 & 7.305597 & 91.98182 & 0.712585 \\
9 & 0.103559 & 7.279115 & 91.81644 & 0.904446 \\
10 & 0.109904 & 7.261307 & 91.6016 & 1.13709 \\
\hline
\end{tabular}

Table 5. Variance decomposition of difference in benchmark interest rates between the United States and China

\begin{tabular}{ccccc}
\hline Period & S.E. & $\begin{array}{c}\text { Onshore Renminbi-Dollar } \\
\text { Exchange Rate }\end{array}$ & $\begin{array}{c}\text { Difference in Inflation Rates } \\
\text { between United States and China }\end{array}$ & $\begin{array}{c}\text { Difference in Benchmark Interest Rates } \\
\text { between United States and China }\end{array}$ \\
\hline 1 & 0.639955 & 7.482227 & 0.019738 & 92.49804 \\
2 & 0.888619 & 11.12251 & 6.585891 & 82.2916 \\
3 & 1.021147 & 12.91771 & 11.70699 & 75.37529 \\
4 & 1.090575 & 13.85857 & 17.24014 & 68.90129 \\
5 & 1.127271 & 14.2186 & 21.78166 & 63.99974 \\
6 & 1.146186 & 14.27342 & 25.64629 & 60.08028 \\
7 & 1.155628 & 14.14709 & 28.83206 & 57.02085 \\
8 & 1.160203 & 13.9173 & 31.48134 & 54.60137 \\
9 & 1.162566 & 13.62803 & 33.68676 & 52.68521 \\
10 & 1.164187 & 13.30678 & 35.53458 & 51.15864 \\
\hline
\end{tabular}

Table 4 shows the onshore renminbi-dollar exchange rate being affected by its own perturbation of 7.305597 in the $7^{\text {th }}$ period, whereupon the amplitude of disturbance effect then starts to decrease. A difference in inflation rates between the United States and China reaches the maximum in the $1^{\text {st }}$ period, and then gradually decreases to 91.6016 in the $10^{\text {th }}$ period. However, the difference in the benchmark interest rates between the United States and China -which is only 1.16 in the $10^{\text {th }}$ period - has little ultimate effect on the onshore renminbi-dollar exchange rate.

Table 5 shows the onshore renminbi-dollar exchange rate being affected by its own perturbation of 14.27342 in the $7^{\text {th }}$ period. The amplitude of the disturbance effect then begins likewise to decrease. The difference in inflation rates between the United States and China increases rapidly in magnitude, with the $10^{\text {th }}$ period being 35.53458. Meanwhile, the impact in the difference in benchmark interest rates between the United States and China on the onshore renminbi-dollar exchange rate continues to decline from 92.49804 in the $1^{\text {st }}$ period to only 51.15864 in the $10^{\text {th }}$ period. 


\section{Policy Implications}

The current Shibor quotation mechanism features several limitations. Specifically, the Shibor price level could be manipulated, as it is primarily based on interest rates set by quotation rather than by trading system. To improve the Shibor quotation mechanism, the number of banks or related entities which give quotations should be expanded so that Shibor can reflect the financial liquidity more accurately and effectively. In addition, the application of Shibor should be enhanced by means of encouraging development and the promotion of more Shibor-based financial products.

Since short-term Shibor varieties entail high activity while long-term Shibor varieties are somewhat lower in trading volume, the quotation is not symmetric. Thus, it has a low reference value. Hence, the influence of the medium-term and long-term Shibor quotation on the market deserves more attention. The quotation of medium-term and long-term Shibor could be given after taking into account the medium-term and long-term pledge repurchase agreement and interest rate of government bonds. This could effectively improve the position and reliability of Shibor as the reference point for medium-term and long-term financial liquidity, and ultimately contribute to the marketization and transparency of benchmark interest rates.

Although the current Chinese exchange rate system has been transformed into a controlled floating exchange rate, the marketization of the exchange rate is still limited by forced settlement, quota management, and other related policies. As a result, China should improve the formation mechanism of the onshore exchange rate and promote the process of marketization. Specifically, the marketization of the exchange rate can be promoted by extending the floating range of the exchange rate, therein avoiding frequent administrative intervention, enhancing the bargaining power of participants of the currency market, and ultimately increasing overall foreign exchange leverage under controllable risk.

\section{Conclusion}

This paper analyzes the relationship between Shibor, an indicator of financial liquidity of China, and the onshore renminbi-dollar exchange rate. We find that Shibor is inversely related to the onshore renminbi-dollar exchange rate under the direct quotation, which is consistent with the theory of purchasing power parity, the theory of interest rate parity, and the theory of balance of payments. Variables such as the difference in inflation rates between the United States and China, the difference in benchmark interest rates between the United States and China, the difference in GDP growth rates between the United States and China, and the trade balance between the United States and China were likewise examined in this paper.

Empirical results show that Shibor and the onshore renminbi-dollar exchange rate have a long-term one-way causal relationship, and they move in opposite direction. The onshore renminbi-dollar exchange rate is not a Granger cause of Shibor, while Shibor, however, has a significant impact on the onshore renminbi-dollar exchange rate.

This finding is generally consistent with the current macro-economic situation in China. Government control is still the main factor that influences the exchange rate and interest rates, and capital flow is likewise limited by policies. Thus, the relationship between the interbank offered rate and the onshore exchange rate is one-way, where reacting effectively is, however, not significant.

\section{References}

Baxter, M. (1994). Real Exchange Rates and Real Interest Differentials: Have We Missed the Business-Cycle Relationship? Journal of Monetary Economics. https://doi.org/10.1016/0304-3932(94)90012-4

Dreger, C. (2008). Does the Nominal Exchange Rate Regime Affect the Real Interest Parity Condition?. North American Journal of Economics \& Finance, 21(3), 274-285. https://doi.org/10.1016/j.najef.2010.01.001

Engel, C. M. (2011). The Real Exchange Rate, Real Interest Rates, and the Risk Premium. SSRN Electronic Journal. https://doi.org/10.2139/ssrn.1934728

Krugman, P., \& Obstfeld, M. (1997). Short-Run Independence of Monetary Policy under Pegged Exchange Rates and Effects of Money on Exchange Rates and Interest Rates. Journal of Money, Credit \& Banking, (4), 783-806.

Raymond, W. (2001). Price and Volatility Spillovers between Interest Rate and Exchange Value of the US Dollar. Global Finance Journal, 12(1), 95-107. https://doi.org/10.1016/S1044-0283(01)00021-7

Shen, G. B. (2002). Relations between Exchange Rate and Interest Rate: A Case Study of Thailand from 1993 to 2000 (in Chinese). World Economy, (5), 10-22. 
Wong, A. J., \& Lin, N. N. (2007). Research on Interaction between Nominal Exchange Rate and Interest Rate (in Chinese). Economic Research, (10), 56-67.

Xue, H. L. (2003). The Linkage of Interest Rate and Exchange Rate in A Dynamic Money Market (in Chinese). Central Party School of the Communist Party of China.

Yang, L. (2011). Interaction between Interest Rate and Exchange Rate from the Perspective of Balanced Economy (in Chinese). East China Economic Management, 25(6), 79-84.

\section{Copyrights}

Copyright for this article is retained by the author(s), with first publication rights granted to the journal.

This is an open-access article distributed under the terms and conditions of the Creative Commons Attribution license (http://creativecommons.org/licenses/by/4.0/). 